\title{
CrimRxiv
}

\section{The Second Amendment}

\section{on Trial: Critical Essays on}

District of Columbia v.

\section{Heller}

Saul A. Cornell, Nathan Kozuskanich

Published on: Jul 12, 2013

DOI: $10.21428 / c b 6 a b 371 . d c 498 a 24$

License: Creative Commons Attribution 4.0 International License (CC-BY 4.0). 
